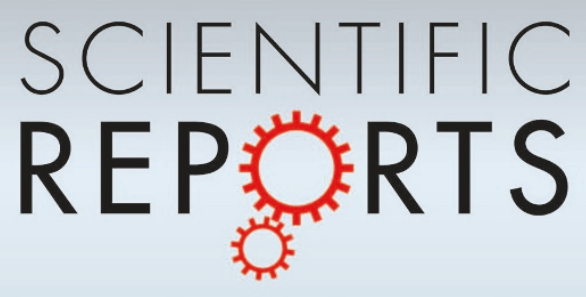

\title{
open Mesostructural Bi-Mo-O catalyst: correct structure leading to high performance
}

SUBJECT AREAS:

SURFACE ASSEMBLY

CATALYST SYNTHESIS

NANOPARTICLES

HETEROGENEOUS CATALYSIS

Received

1 July 2013

Accepted

4 September 2013

Published

14 October 2013

Correspondence and requests for materials should be addressed to

W.D. (dingwp@nju. edu.cn)

\author{
Li Wang' ', Bo Peng' ', Luming Peng' ', Xuefeng Guo', Zaiku Xie² \& Weiping Ding'
}

\begin{abstract}
'Key Lab of Mesoscopic Chemistry, the School of Chemistry and Chemical Engineering, Nanjing University, Nanjing 210093, China, ${ }^{2}$ Shanghai Research Institute of Petrochemical Technology, Shanghai 201208, China.
\end{abstract}

Structure-activity relationship has been one of the main topics of research on catalysts all the time. Component and structure are the two moieties governing the performance of solid materials as catalysts. Multicomponent bismuth molybdates are well known catalysts for propene oxidation but pure crystalline phases of bismuth molybdate are inactive for the reaction. We have designed mesostructural Bi-Mo-O catalyst with pure bismuth molybdate nanocrystals attached to molybdenum oxide nanobelts and found it is a high performance catalyst for the reaction, though the two domains themselves are inactive. The strongly expitaxial interaction between the two domains causes the lattice shrinkage and distortion of the bismuth molybdate nanocrystals and extremely promotes their catalytic activity toward propene oxidation while keeping high selectivity at the same time. The results are instructive for design of nano oxide catalysts with mesostructures leading to high performance.

W ith the progress of materials science, researchers start to talk about mesoscale science, as the next big thing following the nanoscale science ${ }^{1}$. As the important content of nanoscale science, the research on nano catalysts has been carried out world widely in the past two decades and wonderfully catalytic properties of nanoparticles have been continuously unveiled. Many catalysts, with well-defined size, shape and exposed facet, including metals, bimetallic particles, and binary oxides, show highly catalytic performance for corresponding reactions $\mathrm{s}^{2-9}$. The catalytic adjustment of nanoparticles by the electronic donation between the nanoparticles and support or ligands is also recognized widel $y^{2-9,10}$. However, it is seldom reported that strongly structural interactions among the nano domains of a catalytic assembly significantly promote their catalytic properties. We report here a successful design of Bi-Mo-O catalyst with bismuth molybdate nanocrystals attached to molybdenum oxide nanobelts as oxidation catalyst showing high performance for propene oxidation, which would be an example of mesostructural catalyst with strongly structural interaction between its moieties, considering both the single phase of bismuth molybdate and molybdenum oxide are inactive for the reaction.

The multicomponent bismuth molybdates are well known catalysts for propene oxidation ${ }^{11-18}$. The bismuth is considered necessary component, but none of the single phases of bismuth molybdate are active for the reaction, as summarized by Ueda et al. ${ }^{15}$. Commonly, up to ten components are mixed to manufacture industrial catalyst with complicated procedures to modify activity while retaining selectivity, as results of a mass amount of, or high through tests. Could the well-known catalysts be re-designed with the concepts of nanoscale/mesoscale science in a correct and clear structure with simple composition but high performance? Meso, at here, means a size larger than nano and composed of nano building blocks and also a complexity with synergistic interactions among the nano building blocks. Figure 1 shows the design thoughts of mesostructural Bi-Mo-O catalyst with $\mathrm{MoO}_{3}$ nanobelts and $\mathrm{Bi}_{2}\left(\mathrm{MoO}_{4}\right)_{3}$ nanocrystals as building blocks. The interaction among them causes strong adjustment in structural as well as electronic properties of bismuth molybdate, which is much more active for propene oxidation even compared with industrial catalysts.

The nano bismuth molybdates, however, have been hardly ever reported due to the low melting point of bismuth oxide and the sublimation property of molybdenum oxide ${ }^{19}$ and both the two components have relatively small crystal energy, which causes them easy sintering at elevated temperatures. To understand them in depth in new ways has called up re-design with meso structure, i.e., assembly with nano building blocks of Bi-Mo-O and strong interactions among them. We have reported that ferric molybdate nanotubes show novel catalytic property for the propene oxidation under ambient condition $\mathrm{s}^{20,21}$. For mesostructural Bi-Mo-O catalyst, the attachment of well-defined nanocrystals of bismuth molybdate to well-defined nanobelts as a host, constituting the meso structure, is the successful structure we tested with the only two metallic elements, i.e., bismuth and molybdenum, which shows surprisingly high performance for propene oxidation with specific activity two orders of magnitude higher than the single phase bismuth molybdate while keeping high selectivity. The promotion is mainly due to 
(a)

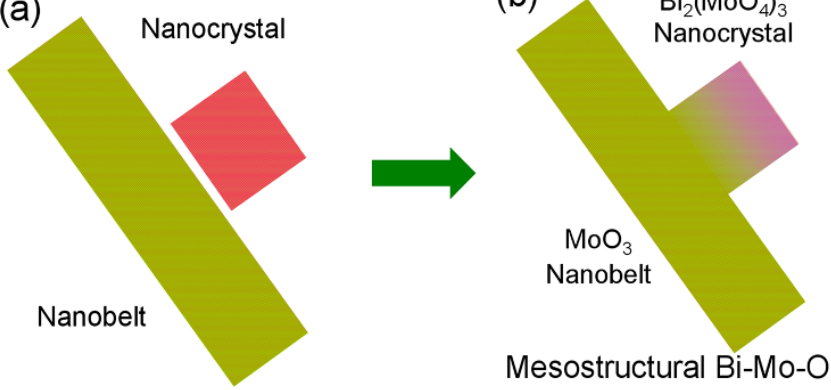

Figure $1 \mid$ Mesostructural Bi-Mo-O catalyst constructed from $\mathrm{MoO}_{3}$ nanobelts and $\mathrm{Bi}_{2}\left(\mathrm{MoO}_{4}\right)_{3}$ nanocrystals.

the strongly structural interactions between the two nano building blocks, which causes the lattice shrinkage and distortion of the bismuth molybdate nanocrystals and then higher mobility of lattice oxygen active for the reaction.

\section{Results}

The preparation of the materials is described in method section. Figure $2 \mathrm{a}$ depicts the SEM image of the mesostructural Bi-Mo-O catalyst, denoted as MoBi-m, with the structure in accordance with the Fig. 1, after heat treatment at $693 \mathrm{~K}$. Many knots in the size of 20 40 nm uniformly attached to the nanobelts are visible. It is the bismuth molybdate nanocrystals closely attached to $\mathrm{MoO}_{3}$ nanobelts and the latter's electronic microscope image is shown in Fig. 2b. The single crystalline and orthorhombic $\mathrm{MoO}_{3}$ nanobelts are several microns in length and their rectangular cross section is about $\sim 20$ $\times 100 \mathrm{~nm}$ in width (Fig. 2b, inset). The heat treatment of $\mathrm{MoO}_{3}$ nanobelts with deposited bismuth species at $693 \mathrm{~K}$ in air results in the formation of nanocrystals (NCs) of bismuth molybdate located on the $\mathrm{MoO}_{3}$ nanobelts, NCs@NBs, as shown in Figs. 2a and 2c. The knots with clear edges and corners on the nanobelts are uniformly in the sizes of $20 \sim 40 \mathrm{~nm}$.

The crystal structures of the samples are examined by XRD and the results are shown in Fig. 2e. The nanobelts with deposited bismuth species before heat treatment give only the diffraction peaks from $\mathrm{MoO}_{3}$, implying the bismuth species on the nanobelts is amorphous at this stage. After heating at $693 \mathrm{~K}$, besides the peaks indexed to the $\mathrm{MoO}_{3}$, all the additional XRD peaks are indexed to $\alpha-\mathrm{Bi}_{2}\left(\mathrm{MoO}_{4}\right)_{3}$ (JCPDS 70-1396). The lattice parameters of the nanocrystals of $\alpha$ $\mathrm{Bi}_{2}\left(\mathrm{MoO}_{4}\right)_{3}$, in monoclinic structure, are calculated and also listed in Fig. 2e. Noteworthy that these values respectively shrink 5.6\%, 1.4\%, and $1.9 \%$, compared with those of the single phase $\alpha-\mathrm{Bi}_{2}\left(\mathrm{MoO}_{4}\right)_{3}$. The XRD pattern of a single phase $\alpha-\mathrm{Bi}_{2}\left(\mathrm{MoO}_{4}\right)_{3}$ sample, denoted as MoBi-c, synthesized with a traditional method $^{22}$, is also depicted in the Fig. 2e, which should be the most stable crystal phase of bismuth molybdate on molybdenum oxide nanobelts.

The HRTEM image on the interface between the nanobelt and the nanocrystal is shown as Fig. $2 \mathrm{~d}$. The visible lattice fringes with $d$ spacings of $\sim 3.82$ and $\sim 3.15 \AA$ respectively correspond to the (100) planes of $\mathrm{MoO}_{3}$ and the $(-221)$ planes of $\alpha$-bismuth molybdate, indicating the nanobelts elongate along the [001] direction of $\alpha-\mathrm{MoO}_{3}$ and the lateral facet belong to the $\{100\}$ faces of $\alpha-\mathrm{MoO}_{3}$. Unfortunately, the most clear lattice fringes for the $\alpha-\mathrm{Bi}_{2}\left(\mathrm{MoO}_{4}\right)_{3}$ are from the $(-221)$ planes, which do not parallel to the interface and also the (100) plane of molybdenum oxide. By observations on more than ten knots, however, the angles between the (100) planes of $\mathrm{MoO}_{3}$ and the $(-221)$ planes of $\alpha-\mathrm{Bi}_{2}\left(\mathrm{MoO}_{4}\right)_{3}$ are found to be the same, i.e., $72^{\circ}$. Based on the results and the crystal knowledge of bismuth molybdate, the planes parallel to the $\{100\}$ planes of $\alpha$ $\mathrm{MoO}_{3}$ can be concluded as the (011) planes of the $\alpha-\mathrm{Bi}_{2}\left(\mathrm{MoO}_{4}\right)_{3}$. This means the knots on the $\mathrm{MoO}_{3}$ nanobelts are single crystal $\alpha$ $\mathrm{Bi}_{2}\left(\mathrm{MoO}_{4}\right)_{3}$ nanocrystals with their (011) crystal planes paralleling
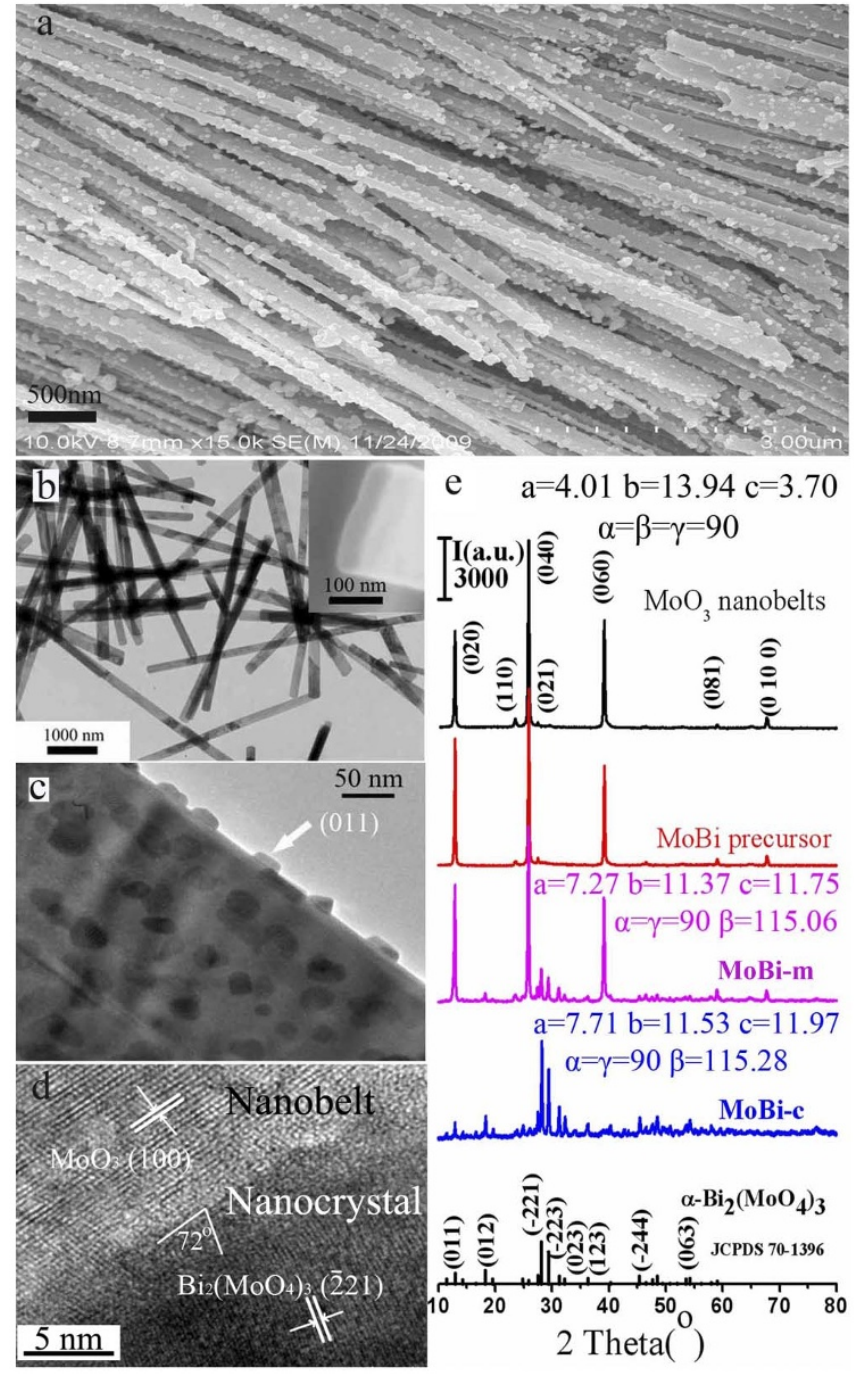

Figure $2 \mid$ (a) SEM image of mesostructural $\mathrm{Bi}_{2}\left(\mathrm{MoO}_{4}\right)_{3} / \mathrm{MoO}_{3}$ with nanocrystals of bismuth molybdate on $\mathrm{MoO}_{3}$ nanobelts; (b) TEM image of the $\mathrm{MoO}_{3}$ nanobelts (inset is the SEM image of one $\mathrm{MoO}_{3}$ nanobelt at one end.); (c) TEM image of a single $\mathrm{MoO}_{3}$ nanobelt with $\mathrm{Bi}_{2}\left(\mathrm{MoO}_{4}\right)_{3}$ nanocrystals; (d) HRTEM of the interface between an $\alpha-\mathrm{Bi}_{2}\left(\mathrm{MoO}_{4}\right)_{3}$ nanocrystal and the $\mathrm{MoO}_{3}$ nanobelt; (e) X-ray powder diffraction patterns of the samples corresponding to the images. ( $\mathrm{a}, \mathrm{b}$ and $\mathrm{c}$ in angstrom; $\alpha, \beta$ and $\gamma$ in degree.)

to the $\{100\}$ planes, one of the lateral surfaces, of the $\mathrm{MoO}_{3}$ nanobelts. As to the nano bismuth molybdate, it is firstly reported in so small and homogeneous size.

Figures $3 \mathrm{a}$ and $3 \mathrm{~b}$ show the two-dimensional $2 \times 2$ cell structures of the (100) and (010) atomic planes of $\mathrm{MoO}_{3}$, which are the two lateral facets of the $\mathrm{MoO}_{3}$ nanobelts. Fig. 3c depicts the (011) atomic plane of bismuth molybdate. Although the two-dimensional symmetries of the faces of $\alpha-\mathrm{MoO}_{3}$ and $\alpha-\mathrm{Bi}_{2}\left(\mathrm{MoO}_{4}\right)_{3}$ are different, they can match well with the (100) and/or (010) planes of $\alpha-\mathrm{MoO}_{3}$ and the (011) plane of $\alpha-\mathrm{Bi}_{2}\left(\mathrm{MoO}_{4}\right)_{3}$, in the manner shown as the Fig. $3 \mathrm{~d}$, with which the mismatches between the two planes of $\mathrm{MoO}_{3}$ and the (011) plane of $\alpha-\mathrm{Bi}_{2}\left(\mathrm{MoO}_{4}\right)_{3}$ are both less than two percents. This should be the cause that the nano $\alpha-\mathrm{Bi}_{2}\left(\mathrm{MoO}_{4}\right)_{3}$ shrink their crystal parameters, as disclosed by XRD. The epitaxial growth compensates the energy for the shrinkage and deformation of the $\alpha-\mathrm{Bi}_{2}\left(\mathrm{MoO}_{4}\right)_{3}$. Fig. $3 \mathrm{e}$ schematically shows the mesostructure of the Bi-Mo-O catalyst.

Meanwhile, the epitaxial attachment of the bismuth molybdate nanocrystals on the molybdenum oxide nanobelts with the lattice 


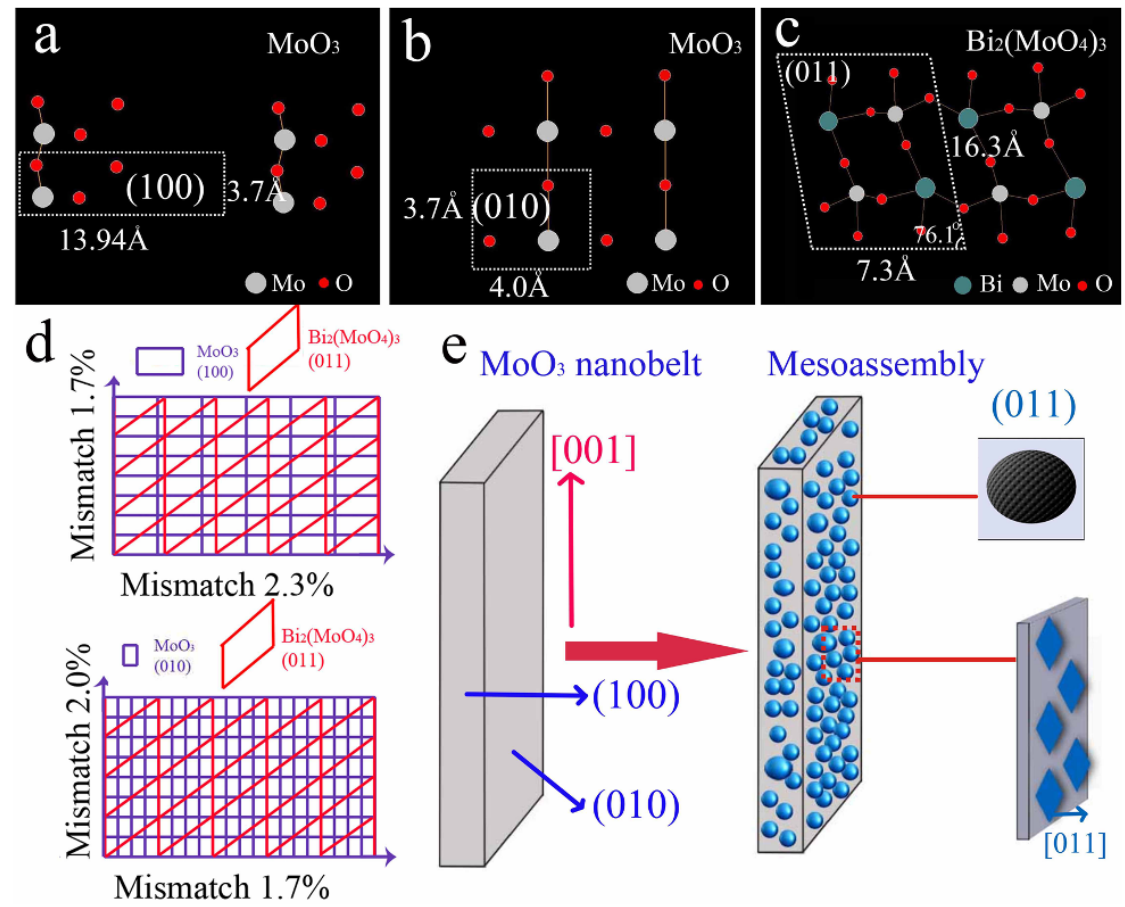

Figure $3 \mid$ (a), (b), (c) The two-dimensional structure of the crystal planes: the (100) and (010) atomic planes of $\mathrm{MoO}_{3}$ and the (011) atomic plane of $\alpha$ $\mathrm{Bi}_{2}\left(\mathrm{MoO}_{4}\right)_{3}$. (d) The schematic presentation for epitaxial growth of $\mathrm{Bi}_{2}\left(\mathrm{MoO}_{4}\right)_{3}$ on the surface of $\mathrm{MoO}_{3}$. (e) The schematic diagram of the formation of $\alpha-\mathrm{Bi}_{2}\left(\mathrm{MoO}_{4}\right)_{3}$ nanocrystals on the $\{100\}$ atomic planes of $\mathrm{MoO}_{3}$.

shrinkage and deformation also causes the changes in the spectroscopic properties of the sample, e.g., the infrared, Raman spectra (Figs. $4 \mathrm{a}$ and $4 \mathrm{~b}$ ) and XPS (Figs. $4 \mathrm{c}$ and $4 \mathrm{~d}$ ). For IR spectra, the main differences are two bands, i.e., $980 \sim 1000 \mathrm{~cm}^{-1}$, corresponding to the $\mathrm{Mo}=\mathrm{O}$ vibration, and $850 \sim 870 \mathrm{~cm}^{-1}$, corresponding to the Mo-Obonds ${ }^{23}$. The red shift of the IR absorption peaks of MoBi-m sample, compared with the corresponding IR peaks of MoBi-c sample, indicates smaller bond energies between Mo and oxygen over the MoBi$\mathrm{m}$ sample, leading to more active oxygen species of the catalyst. From Raman spectra, some modes of the bismuth molybdate nanocrystals are inactive, compared with the $\mathrm{MoBi}-\mathrm{c}$, as pointed by arrow in the figure, implying the strong affection of the substrate $\mathrm{MoO}_{3}$ nanobelts. The XPS spectra of MoBi-m indicates, by deconvoluting to $\mathrm{MoO}_{3}$ and $\mathrm{Bi}_{2}\left(\mathrm{MoO}_{4}\right)_{3}{ }^{24}$, the molybdenum in the bismuth molybdate nanocrystals exhibits a lower $3 \mathrm{~d}$ binding energy, then less positively charged, than that of single phase bismuth molybdate, i.e. the oxygen around the Mo has more electrophilicity, which facilitates the oxygen attacking the $\mathrm{C}-\mathrm{H}$ bond of hydrocarbons.

For further understanding the properties of the lattice oxygen, the exchange of lattice oxygen, mainly ${ }^{16} \mathrm{O}$, with ${ }^{17} \mathrm{O}$ is carried out and the ${ }^{17} \mathrm{O}-\mathrm{NMR}$ spectra are recorded and the results are shown Fig. 5a. Generally, four peaks are observed for the MoBi-m and MoBi-c samples. The peaks at $\sim 317$ and $\sim 394 \mathrm{ppm}$ are attributed to the Mo- ${ }^{17} \mathrm{O}-\mathrm{Bi}$ structure and the peaks at $\sim 744$ and $\sim 815$ ppm belong to the $\mathrm{Mo}^{-17} \mathrm{O}-\mathrm{Mo}$ structure in bismuth molybdate ${ }^{25,26}$. Indeed, some differences in the above four peaks between the two samples are observed and reflect the subtle environmental change of oxygen from single phase bismuth molybdate to the bismuth molybdate attached to $\mathrm{MoO}_{3}$ nanobelts. Additionally, almost no signals are observed with the $\mathrm{MoO}_{3}$ nanobelts, reflecting the difficulty in oxygen exchange of molybdenum oxide with the gaseous oxygen, which is totally inactive for the reaction. Fig. $5 b$ lists the results of $\mathrm{H}_{2}$ temperature-programmed reduction of the two catalysts and, obviously, the MoBi-m is more active and reducible by hydrogen at much lower temperatures and, correspondingly, the profiles of $\mathrm{O}_{2}$ temperatureprogrammed desorption depicted in Fig. $5 \mathrm{c}$ gives similar results, indicating the higher mobility of the lattice oxygen in MoBi-m than in MoBi-c caused by the arrangement of the meso structure.

The catalytic properties of both the catalysts, MoBi-m and MoBi-c, for selective oxidation of propene are measured and shown as the Fig. 6a. The MoBi-m is active at much lower temperatures. With the temperature increasing, the propene conversion increases sharply with stable selectivity to acrolein and acrylic acid (>96\%). In contrast, the single phase $\alpha$-bismuth molybdate catalyst (MoBi-c) starts to be active at the temperatures higher than $600 \mathrm{~K}$. The TOF of the reaction normalized with the active surface area of the two samples and kinetic parameters of the reaction are also measured and listed in Table 1.

The results indicate that the TOF of propene on MoBi- $\mathrm{m}$ is $\sim$ two orders of magnitude higher than that on MoBi-c catalyst. By measuring the catalytic kinetics over the two catalysts at $623 \mathrm{~K}$ using the steady state reaction method similar to that reported in Ref. 13,27 and described in Supplementary and Additional Information, the activation energy (Ea) for propene conversion, in the temperature range of $583 \sim 623 \mathrm{~K}$, over $\mathrm{MoBi}-\mathrm{m}(157 \mathrm{~kJ} / \mathrm{mol})$ is found to be lower than that over MoBi-c catalyst $(199 \mathrm{~kJ} / \mathrm{mol})$. The difference in the activation energy offers about three thousand times of reaction rate over the MoBi-m higher than that over MoBi-c catalyst at the reaction temperature used. Therefore, the catalyst MoBi-m possesses active sites much more active for propene conversion, because of the unique assembly and the orientation of bismuth molybdate nanocrystals. Due to the very small ratio of active surface of MoBi$\mathrm{m}$, however, the MoBi-m catalyst offers about 26 times of reaction rate constant higher than over the MoBi-c catalyst at the end. It appears the single crystal molybdenum oxide nanobelts set the attached and distorted bismuth molybdate nanocrystals in this specific direction more energetic and effective. (Figs. S1, S2 and S3, Supplementary and Additional Information)

Furthermore, the high activity for propene conversion of the MoBi-m is very stable in tested $120 \mathrm{~h}$ continuous reaction, as shown in Fig. 6b. Subsequent characterizations of XRD and TEM on the used catalyst show the morphology and crystallization of the meso 

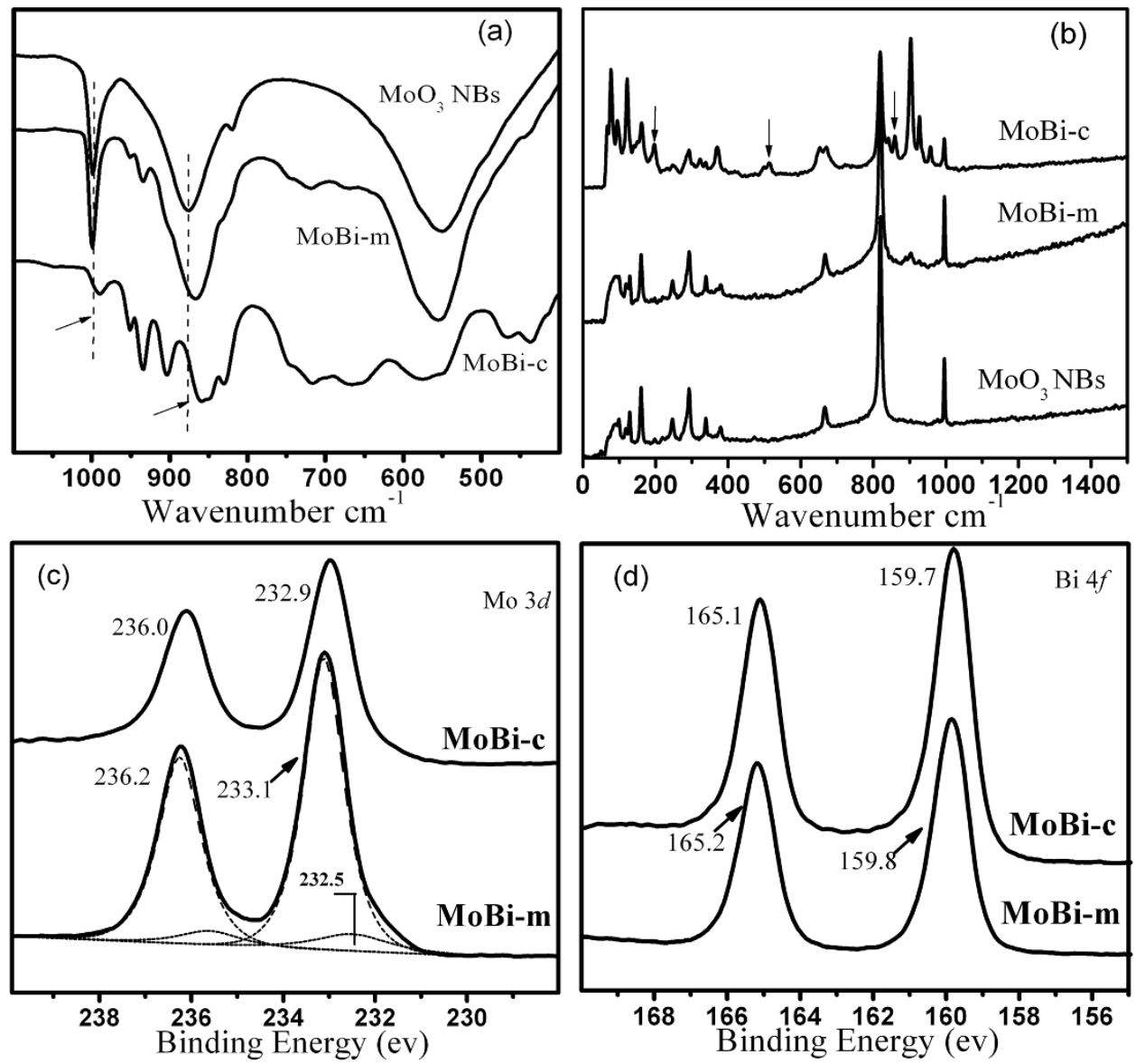

Figure $4 \mid$ (a) FT-IR and (b) Raman spectra of the samples; (c) and (d) XPS spectra of the $\alpha$-bismuth molybdate samples.

structure of nanocrystals and nanobelts are essentially unchanged during the $120 \mathrm{~h}$ reaction. The unique performance is comparable to or even better than the multicomponent bismuth molybdate documented $^{28}$. Experimentally, the current MoBi-m catalyst is compared with the industrial catalyst by Shanghai Research Institute of Petrochemical Technology, Sinopec. Under the same conditions, the catalytic performance of MoBi-m catalyst indeed is better than the industrial multicomponent catalyst (Table S1, Supplementary and Additional Information). Noteworthy that the ratio of acrolein and acrylic acid in the products over the MoBi-m catalyst is higher than that over the multicomponent catalyst, which implies that the faster desorption of acrolein from the MoBi-m catalyst may be the cause of higher selectivity of MoBi-m (Table S1).

\section{Discussion}

Meso also means a kind of complication and includes many more interactions among its nano constituents. The thoughts of meso science are very applicable for catalysis research, considering the ultimate example of catalyst, enzyme, consisting of multi parts as smart molecular machine with extremely subtle cooperation among
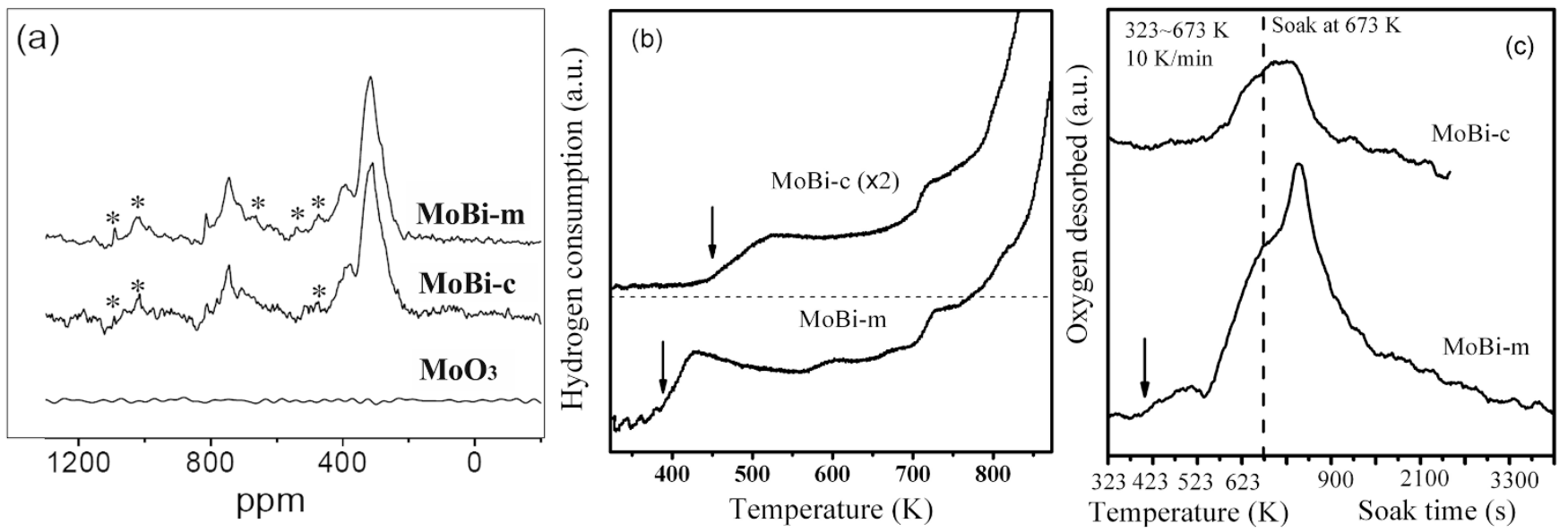

Figure $5 \mid$ (a) ${ }^{17} \mathrm{O}$ magic angle spinning (MAS) NMR spectra of MoBi-m, MoBi-c and $\mathrm{MoO}_{3}$ (Asterisks denote spinning sidebands); (b) Results of $\mathrm{H}_{2}-$ TPR (temperature-programmed reduction); (c) $\mathrm{O}_{2}$-TPD (temperature-programmed desorption). 

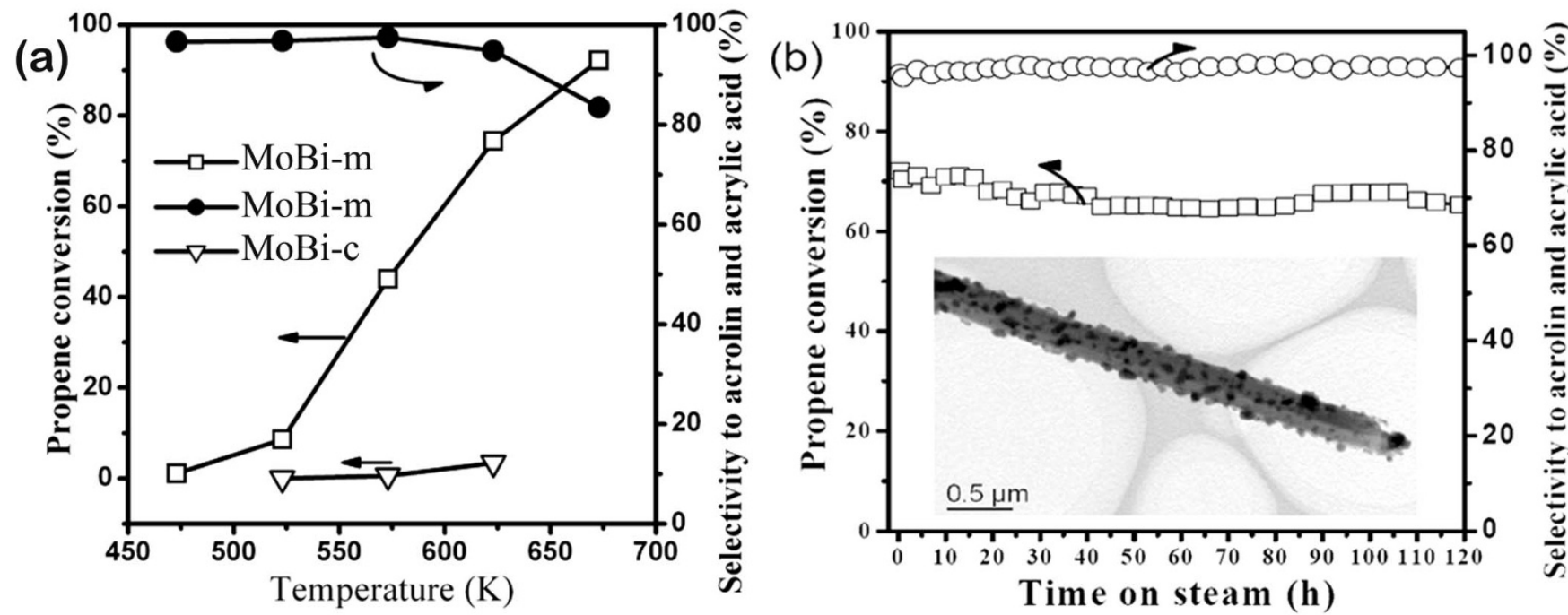

Figure $6 \mid$ (a) Temperature dependence of catalytic behaviours of the $\alpha$-bismuth molybdate samples. Catalyst: 0.35 g; propene: $3 \mathrm{kPa}$; air: $98.3 \mathrm{kPa}$; space velocity: $2200 \mathrm{ml} \mathrm{g}^{-1} \mathrm{~h}^{-1}$. (b) Time dependence of catalytic behaviours of the MoBi-m for the oxidation of propene by air. Inset shows one nanobelt after the reaction. The other products were acetone, isopropanol, and $\mathrm{CO}_{\mathrm{x}} \cdot(623 \mathrm{~K})$.

them. The current investigation is a primary exploration on the mesostructural Bi-Mo-O catalyst composed of the nano building blocks of molybdenum oxide and bismuth molybdate toward high performance.

At present time, due to the more serious consideration on environment and energy, the innovation on new catalytic materials brought by the upgrade of practical industry catalysts with more efficiency and less emission is very important and practically required $^{29,30}$, for the most of industrial processes have used catalysts, which makes huge contribution to human's social life. The present findings offer a line clear for the next work moves along on the development of new catalytic materials, special for oxide catalysts, which constitute a large sort of practical catalysts, in mesostructures with strong structural and electronic interaction among their nano building blocks.

\section{Methods}

Synthesis of $\mathrm{MoO}_{3}$ nanobelts. The single crystal $\mathrm{MoO}_{3}$ nanobelts are prepared according to ref. 31,32 . Typically, $\mathrm{MoO}_{3}$ powders (30 mmol, $4.32 \mathrm{~g}$ ) dissolved completely in $30 \%$ aqueous solution of hydrogen peroxide $(66.0 \mathrm{ml})$ by stirring at $303 \mathrm{~K}$. The resultant solution was transferred into a Teflon-lined stainless steel autoclave until it was $60-70 \%$ filled. The autoclave was then sealed and maintained at $453 \mathrm{~K}$ for $24 \mathrm{~h}$. After cooling naturally to room temperature in ambient surroundings, the precipitate was collected after centrifuging, thoroughly rinsed with deionized water, and dried at $313 \mathrm{~K}$.

Synthesis of Bi-Mo-O mesostructure. In a typically synthesis, $\mathrm{Bi}\left(\mathrm{NO}_{3}\right)_{3}(2 \mathrm{mmol})$ was dissolved in glycerol $(10 \mathrm{ml})$ completely at $333 \mathrm{~K} . \mathrm{MoO}_{3}$ nanobelts $(10 \mathrm{mmol})$ and ethanol $(330 \mathrm{ml})$ were added to form the mixed solution. Under vigorous agitation, deionized water $(50 \mathrm{ml})$ was pumped continuously at a rate of $0.01 \mathrm{ml}$ $\mathrm{min}^{-1}$ into the above solution at $353 \mathrm{~K}$. After stirring for $24 \mathrm{~h}$, the precipitate was collected by centrifuging and thoroughly rinsed and dried at $313 \mathrm{~K}$. Then, the precipitate was calcined at $693 \mathrm{~K}$ for $10 \mathrm{~h}$ in the static air.
Characterization. Powder XRD measurements were performed with a Philips X'Pert MPD Pro X-ray diffractometer with graphite-monochromated high-intensity $\mathrm{Cu} \mathrm{K \alpha}$ radiation $(0.15418 \mathrm{~nm})$ at $40 \mathrm{kV}$ and $40 \mathrm{~mA}$. TEM images were recorded with a JEM100 S Electron Microscope (JEOL) at an accelerating voltage of $80 \mathrm{kV}$. HRTEM was performed with a JEOL JEM-2010 instrument at an acceleration voltage of $200 \mathrm{kV}$. The nitrogen sorption isotherms were measured at liquid-nitrogen temperature on an ASAP 2020 apparatus. FT-IR spectra were recorded under vacuum condition in a Bruker VERTEX FT-IR spectrometer. Raman spectra were recorded in a Bruker Multi RAM FT-Raman spectrometer. (Laser source: $1064 \mathrm{~nm}$ ). $\mathrm{H}_{2}$ temperatureprogrammed reduction was performed using a Xianquan AutoSorption TP-5080 instrument, Tianjin, China. Typically, the sample $(10 \mathrm{mg})$ was pretreated in a quartz reactor with air flow at $573 \mathrm{~K}$ for $2 \mathrm{~h}$ followed by purging with Argon. After the sample was cooled to $373 \mathrm{~K}$, a $\mathrm{H}_{2}-\mathrm{Ar}\left(10 \mathrm{vol} . \% \mathrm{H}_{2}\right)$ gas flow was introduced into the reactor, and the temperature was raised to $873 \mathrm{~K}$ at a rate of $10 \mathrm{~K} / \mathrm{min}$. The consumption of $\mathrm{H}_{2}$ was monitored by a thermal conductivity detector. For the measurement of ${ }^{17} \mathrm{O}-\mathrm{NMR}$, the samples were isotopically enriched with ${ }^{17} \mathrm{O}_{2}$ at $773 \mathrm{~K}$ and ${ }^{17} \mathrm{O}$ magic angle spinning (MAS) NMR spectra were obtained with a Bruker Avance III spectrometer at 9.4 Tesla with a $3.2 \mathrm{~mm}$ probe at a spinning rate of $15 \mathrm{kHz}$. A standard Hahn echo $(\pi / 2-\tau-\pi-\tau-$ acquisition) pulse sequence was employed, with the $\pi / 2$ pulse width of $1.1 \mu \mathrm{s}$, corresponding to a radio frequency tip angle of $30^{\circ}$ at about $75 \mathrm{kHz}$ rf power, and a recycle delay of $2 \mathrm{~s} .{ }^{17} \mathrm{O}$ chemical shifts are referenced to $\mathrm{H}_{2} \mathrm{O}$ at $0.0 \mathrm{ppm}$.

Catalytic test and the measurement of catalytic kinetics. The propene oxidation reaction was carried out using a continuous flow fixed bed reactor at atmospheric pressure. Feed gases were delivered by mass flow controllers and the products were analyzed on-line by two gas chromatographs. One of them was equipped with a flame ionization detector (FID) and a thermal conductivity detector (TCD) and the other was equipped with two TCDs. The kinetics of propene oxidation over the two catalysts at $623 \mathrm{~K}$ was measured using the steady state reaction method similar to that reported in Ref. 13,27. For the measurement of kinetic parameters, $0.35 \mathrm{~g}$ catalyst was put in a U-type quartz tube in a furnace and the reaction flow was composed of propene, air and balance $\mathrm{He}$, controlled by mass flow controller. The partial pressure of propene in the reaction mixture was varied from 200 to $800 \mathrm{~Pa}$, and the partial pressure of oxygen was set in the range of $500 \sim 2000 \mathrm{~Pa}$. The measurement was performed at $623 \mathrm{~K}$ and the conversions of propene and oxygen were controlled less than $5 \%$. The reaction rate equation under the conditions used was found as $\frac{d P_{C_{3} H_{6}}}{d t}=k \cdot P_{O_{2}}^{1.5}$. The active energy (Ea) was calculated using Arrhenius equation in the temperature range of $583 \sim 623 \mathrm{~K}$. (Supplementary and Additional Information)

Table 1 | Catalytic performance for propene oxidation by air of the different bismuth molybdate catalysts ${ }^{[a]}$

\begin{tabular}{|c|c|c|c|c|c|c|}
\hline Samples & $\mathrm{S}_{\mathrm{BET}}\left(\mathrm{m}^{2} \mathrm{~g}^{-1}\right)$ & Conversion (\%) & $\mathrm{TOF}^{[\mathrm{b}]} / 10^{3}$ & Selectivity ${ }^{[d]}(\%)$ & $\mathrm{Eq}^{[\mathrm{e]}}(\mathrm{kJ} / \mathrm{mol})$ & $\mathrm{k} \cdot 10^{7[\mathrm{~h}]}$ \\
\hline $\mathrm{MoO}_{3} \mathrm{NBs}$ & 8.8 & $\sim 0$ & $\sim 0$ & - & - & - \\
\hline MoBi-c & 3.2 & 3.3 & 2.4 & 94.9 & 199 & 0.095 \\
\hline MoBi-m & 8.6 & 75.1 & $275^{[c]}$ & 97.1 & 157 & 2.5 \\
\hline
\end{tabular}

[a] Cat.: $0.35 \mathrm{~g}$; propene: $3 \mathrm{kPa}$; air: $98.3 \mathrm{kPa}$; space velocity: $2200 \mathrm{ml} \mathrm{g}^{-1} \mathrm{~h}^{-1}$; temp.: $623 \mathrm{~K}$. [b] TOF is defined as propene molecules converted per surface area per second ( $\mu \mathrm{m}^{-2} \mathrm{~s}^{-1}$ ). According to TEM and SEM results, surface area of bismuth molybdate nanocrystals is calculated as $11 \%$ of that of MoBi-m catalyst. [c] For correct comparison, the conversion of propene is purposely depressed to $\sim 5 \%$ by increasing the space velocity at the same temperature. [d] Acrolein and acrylic acid. [e] The activation energy is measured in the temperature range of $583 \sim 623 \mathrm{~K}$. [h] Rate constant for the propene conversion $\left(\mathrm{mol} \mathrm{min}^{-1} \mathrm{~Pa}^{1.5}\right)$. 
1. Service, R. F. The next big(ger) thing. Science 335, 1167 (2012).

2. Zhou, K. B. \& Li, Y. D. Catalysis based on nanocrystals with well-defined facets. Angew. Chem. In. Ed. 51, 602-613 (2012).

3. Wang, D. S. \& Li, Y. D. Bimetallic nanocrystals: liquid-phase synthesis and catalytic applications. Adv. Mater. 23, 1044-1060 (2011).

4. Xie, X. W. et al. Low-temperature oxidation of $\mathrm{CO}$ catalysed by $\mathrm{Co}_{3} \mathrm{O}_{4}$ nanorods. Nature 458, 746-749 (2009).

5. Kesavan, L. et al. Solvent-free oxidation of primary carbon-hydrogen bonds in toluene using Au-Pd alloy nanoparticles. Science 331, 195-199 (2011).

6. Oliver-Meseguer, J. et al. Small gold clusters formed in solution give reaction turnover numbers of $10^{7}$ at room temperature. Science 338, 1452-1455 (2012).

7. Armbrüster, M. et al. $\mathrm{Al}_{13} \mathrm{Fe}_{4}$ as a low-cost alternative for palladium in heterogeneous hydrogenation. Nat. Mater. 11, 690-693 (2012).

8. Shiju, N. R. \& Guliants, V. V. Recent developments in catalysis using nanostructured materials. Appl. Catal. 356, 1-17 (2009).

9. Qian, H. F. et al. Total structure determination of thiolate-protected $\mathrm{Au}_{38}$ nanoparticles. J. Am. Chem. Soc. 132, 8280-8281 (2010).

10. Grirrane, A., Corma, A. \& Garcia, H. Gold-catalyzed synthesis of aromatic Azo compounds from anilines and nitroaromatics. Science 322, 1661-1664 (2008).

11. Idol, J. D. Process for the manufacture of acrylonitrile. U.S. Patent 2,904,580 (1959).

12. Keulks, G. W., Hall, J. L., Daniel, C. \& Suzuki, K. The catalytic oxidation of propylene: IV. Preparation and characterization of $\alpha$-bismuth molybdate. J. Catal. 34, 79-97 (1974)

13. Matsuura, I., Schut, R. \& Hirakawa, K. The surface structure of the active bismuth molybdate catalyst. J. Catal. 63, 152-166 (1980).

14. Synder, T. P. \& Hill, C. G. The mechanism for the partial oxidation of propylene over bismuth molybdate catalysts. Catal. Rev.-Sci. Eng. 31, 43-95 (1989).

15. Moro-oka, Y. \& Ueda, W. Multicomponent bismuth molybdate catalyst: A highly functionalized catalyst system for the selective oxidation of olefin. Adv. Catal. 40, 233-273 (1994).

16. Greybowska-Świerkosz, B. Thirty years in selective oxidation on oxides: what have we learned? Top. Catal. 11/12, 23-42 (2000).

17. Grasselli, R. K. Selectivity issues in (amm)oxidation catalysis. Catal. Today $\mathbf{9 9}$ 23-31 (2005).

18. Carranzn, S. R. G., Martín, C., Mateos, R. \& Rives, V. Influence of the active phase structure Bi-Mo-Ti-O in the selective oxidation of propene. Catal. Today 112, 121-125 (2006).

19. Peng, C., Gao, L., Yang, S. W. \& Sun, J. A general precipitation strategy for largescale synthesis of molybdate nanostructures. Chem. Commun. 5601-5603 (2008).

20. Wang, L. et al. Ferric molybdate nanotubes synthesized based on the Kirkendall effect and their catalytic property for propene epoxidation by air. Chem. Commun. 1565-1567 (2009)

21. Wang, L et al. Preparation, Characterization, and Properties of Ferric Molybdate Nanotubes for Propene Epoxidation by Air. Chin. J. Catal. 30, 711-713 (2009).

22. Batist, P. H. A., Bouwens, J. F. H. \& Schuit, G. C. A. Bismuth molybdate catalysts Preparation, characterization and activity of different compounds in the $\mathrm{Bi}-\mathrm{Mo}-\mathrm{O}$ system. J. Catal. 25, 1-11 (1972).

23. Carrazán, S. R. G., Martín, C., Rives, V. \& Vidal, R. An FT-IR spectroscopy study of the adsorption and oxidation of propene on multiphase $\mathrm{Bi}, \mathrm{Mo}$ and $\mathrm{Co}$ catalysts. Spectrochim. Acta. Part A 52, 1107-1118 (1996).

24. Uchida, K. \& Ayame, A. Dynamic XPS measurements on bismuth molybdate surfaces. Surf. Sci. 357-358, 170-175 (1996).
25. Yang, S., Park, K. D. \& Oldfield, E. Oxygen-17 Labelling of Oxides and Zeolites. J. Am. Chem. Soc. 11, 7278-7279 (1989).

26. Emery, J. et al. ${ }^{17} \mathrm{O}$ NMR in room temperature phase of $\mathrm{La}_{2} \mathrm{Mo}_{2} \mathrm{O}_{9}$ fast oxide ionic conductor. Magn. Reson. Chem. 43, 366-371 (2005).

27. Keulks, G. W., Rosynek, M. P. \& Daniel, C. Bismuth molybdate catalysts. Kinetics and mechanism of propylene oxidation. Ind. Eng. Chem. Prod. Res. Develop 10, 138-142 (1971).

28. Dieterle, M., Petzoldt, J. \& Muller-Engel, K. J. Heterogeneously catalyzed partial gas phase oxidation of propene to acrolein. U. S. Patent 225158 (2004).

29. Wittstock, A. et al. Nanoporous gold catalysts for selective gas-phase oxidative coupling of methanol at low temperature. Science 327, 319-322 (2010)

30. Hermans, I., Spier, E. S. \& Neuenschwander, U. Selective oxidation catalysis: opportunities and challenges. Top. Catal. 52, 1162-1174 (2009).

31. Fang, L., Shu, Y., Wang, A. \& Zhang, T. Green synthesis and characterization of anisotropic uniform single-crystal $\alpha-\mathrm{MoO}_{3}$ nanostructures. J. Phys. Chem. C 111, 2401-2408 (2007).

32. Lou, X. W. \& Zeng, H. C. Hydrothermal synthesis of $\alpha-\mathrm{MoO}_{3}$ nanorods via acidification of ammonium heptamolybdate tetrahydrate. Chem. Mater. 14, 4781-4789 (2002).

\section{Acknowledgments}

The authors thank the financial supports from the Ministry of Science and Technology of China (2009CB623504), the National Science Foundation of China $(20673054,21273107)$, and Sinopec Shanghai Research Institute of Petrochemical Technology. Ding WP is grateful to the discussions with Prof. Charles Lieber of Harvard University on nano research and also to the discussion on kinetics with Prof. Enrique Iglesia of the University of California at Berkeley. The helpful comments from Prof. Wataru Ueda of Hokkaido University, Prof. Jingguang Chen of University of Delaware and Prof. Yadong Li of Tsinghua University are highly appreciated.

\section{Author contributions}

W.P.D. contributed to the conception and design of the experiment, analysis of the data and writing the manuscript. L.W. and B.P. carried out design, synthesis and characterization of the catalysts. L.M.P. carried out the measurement of solid NMR and corresponding writing. X.F.G. carried out the measurement of catalytic kinetics. Z.K.X. carried out the evaluation of the catalysts under industrial conditions. All the authors contributed to discussion on the results and preparation of manuscript

\section{Additional information}

Supplementary information accompanies this paper at http://www.nature.com/ scientificreports

Competing financial interests: The authors declare no competing financial interests. How to cite this article: Wang, L. et al. Mesostructural Bi-Mo-O catalyst: correct structure leading to high performance. Sci. Rep. 3, 2881; DOI:10.1038/srep02881 (2013).

This work is licensed under a Creative Commons AttributionNonCommercial-NoDerivs 3.0 Unported license. To view a copy of this license, visit http://creativecommons.org/licenses/by-nc-nd/3.0 